\title{
Impacts of a novel shellfishing gear on macrobenthos in a marine protected area: pump-scoop dredging in Poole Harbour, UK
}

\author{
Leo J. Clarke*, Luciana S. Esteves, Richard A. Stillman and Roger J.H. Herbert \\ Faculty of Science and Technology, Department of Life and Environmental Sciences, Bournemouth University, \\ Fern Barrow, Poole, Dorset BH12 5BB, UK
}

Received 13 June 2017 / Accepted 22 November 2017

Handling Editor: Ellen Kenchington

\begin{abstract}
Understanding the impact of bottom-fishing gears at various scales and intensities on habitats and species is necessary to inform management. In Poole Harbour, UK, a multiple use marine protected area, fishermen utilise a unique "pump-scoop" dredge to harvest the introduced Manila clam Ruditapes philippinarum. Managers need to balance the socio-economic benefits of the fishery with ecological concerns across the region, which has required a revision of by-laws that include both spatial and temporal measures. Within an operational fishery, we used a Before-After-Control-Impact sampling design to assess the impacts of pump-scoop dredging on benthic physical characteristics and community structure in an area where there was no dredging, an area newly opened to dredging and an area subject to high levels of historic dredging. A sampling grid was used in each area to best capture any fishing effort in the newly opened area. Core samples were taken to a depth of $30 \mathrm{~cm}$ within intertidal mudflats. A significant loss of fine sediments was observed in the site subject to high intensity dredging and a significant change in community structure also occurred in both dredged sites throughout the study period. In the newly opened site this was characterised by a relative increase in species richness, including increased abundance of annelid worms, notably Hediste diversicolor and Aphelochaeta marioni and a decline in the abundance of the bivalve mollusc Abra tenuis. These changes, albeit relatively small, are attributed to physical disturbance as a direct result of pump-scoop dredging, although no difference in the classification of the biotope of the site was observed. This is of particular interest to managers monitoring site condition within areas under the new bylaws as the Manila clam is spreading to other protected estuaries in the region.
\end{abstract}

Keywords: Shellfish / dredging / fishing / impacts / marine protected areas / manila clam Ruditapes philippinarum / cockle Cerastoderma edule

\section{Introduction}

In the marine environment the use of bottom-fishing gears is one of the largest sources of anthropogenic disturbance on habitats and species (Dayton et al., 1995; Collie et al., 2000; Kaiser et al., 2006; Martín et al., 2015). However the types of gear employed may vary greatly at local and regional scales, depending on the target species and local physical environment. The increasing introduction of non-native marine species is generally seen as a threat to biosecurity and nature conservation interests (Meyerson \& Reaser, 2002; Bax et al., 2003; Molnar et al., 2008), yet harvestable populations of significant commercial value can emerge that can lead to development of novel fishing techniques by local fishermen (Pranovi et al.,

*Corresponding author: 1clarke@bournemouth.ac.uk
2004). While the impacts of bottom-fishing overall are well understood (Dayton et al., 1995; Collie et al., 2000; Kaiser et al., 2006), it is important to consider the risks of such new or novel gear types where they arise and whether their impacts differ from more established and common fishing gears.

The Manila clam Ruditapes phillipinarum (Adams and Reeve, 1850) (genus synonyms: Venerupis, Tapes) has spread throughout Europe in recent decades and is harvested recreationally and commercially (Pranovi et al., 2004; Beck et al., 2015; Mosbahi et al., 2016). The species was introduced to a number of locations in the United Kingdom in the early 1980 s with the intentions of establishing commercial aquaculture including Poole Harbour on the south coast of the UK (Utting and Spencer, 1991; Britton, 1991; Humphreys et al., 2015). It has since become naturalised in Poole Harbour and has been exploited under a licensed fishery using a "pumpscoop" dredge (Jensen et al., 2005; Humphreys et al., 2015) 


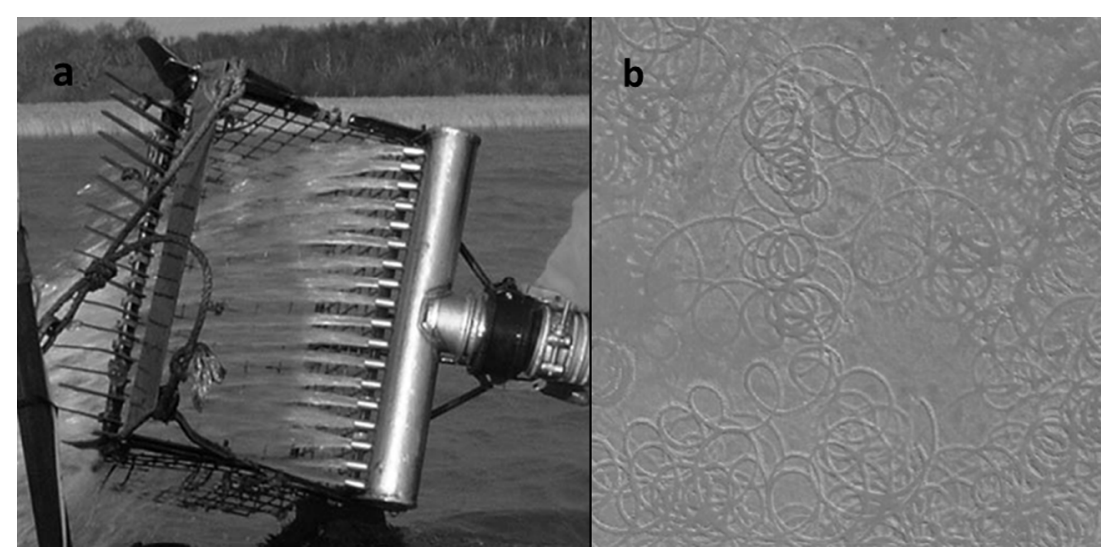

Fig. 1. (a) The pump-scoop dredge used in Poole Harbour, UK. (b) Aerial imagery of scarring from pump-scoop dredging within Poole Harbour. Modified with permission from Jensen et al. (2005) and Footprint Ecology Ltd. (Fearnley et al., 2013) respectively. No scale bar was included in original publication, although the circular scars generally range from 5-15 $\mathrm{m}$ across.

since 1994 (Jensen et al., 2005). The fishery is of significant regional economic importance, with a peak annual value in 2004 of around $£ 1.5$ million (Franklin et al., 2012). Pumpscoop dredges are relatively small $(46 \times 46 \times 30 \mathrm{~cm})$ and penetrate the sediment to a depth of a few centimetres. This method of harvesting is currently unique to this location, and utilises a water pump powered by the vessel's engine to rinse sediment through the rear of the dredge basket as it is towed alongside the vessel (Fig. 1a). This type of dredge is distinct from hydraulic or suction dredges that fluidise the sediment in front of the dredge, and was developed by local fishermen as an improvement to the previously used hand-held clam "scoop", which is a physically demanding gear (Jensen et al., 2005). The dredge is worked on shallow drafted vessels less than $10 \mathrm{~m}$ in length within intertidal and shallow subtidal areas of mud and sandy mud. The common cockle Cerastoderma edule is also harvested using the pump-scoop dredge method, although to a lesser extent than R. philippinarum (cockle landings are $5 \%$ of clam landings. At low tide, extensive dredge scars in a spiral pattern are visible that resemble rounded troughs (Fig. 1b), indicating the vessel movements (Parker and Pinn, 2005; Fearnley et al., 2013). Previous work on the impact of these gears is limited; however there are concerns that they may affect benthic communities, reducing species richness and abundance (Parker and Pinn, 2005).

In protected areas, fisheries and environmental managers must assess and monitor habitat condition to ensure sustainable development and inform management. This study assessed the impacts of pump-scoop dredging through analysis of the biological assemblage and physical characteristics within areas subject to different fishing intensities, therefore contributing to the limited evidence of the environmental impacts of this gear type. We achieved this by answering the following research questions: How does short-term pump-scoop dredging affect macrobenthic communities compared to an un-dredged control area? How does pump-scoop dredging affect the physical benthic environment and sediment characteristics compared to an un-dredged control area? If any, what changes in macrobenthic community structure and biotope characterise these impacts?

\section{Materials and methods}

\subsection{Study area}

Poole Harbour is located in Dorset on the south coast of England (Fig. 2) and comprises extensive areas of mudflats, sandflats and saltmarsh. The harbour covers an area of $36000 \mathrm{~km}^{2}$ at high tide, and is micro-tidal, with a range of $1.8 \mathrm{~m}$ on spring tides and $0.6 \mathrm{~m}$ on neap tides (Humphreys, 2005). Poole Harbour experiences two high tides a day, with a relatively long slack water period at high tide that results in a water level above that of mean tide level for the majority of the day (Humphreys, 2005). The Harbour is designated for its conservation importance as a European Marine Site (EMS) (European Birds Directive 79/409/EEC) and Ramsar site. From September, large numbers $(>25000)$ of migratory waterfowl arrive in the harbour to feed and over-winter.

Due to a historic prevalence of illegal fishing and high risk of disturbance to protected feeding areas for over-wintering birds, a new permit system came into force in the harbour in 2015, replacing the previous management regime under a new by-law. This by-law restricts the use of a dredge to an open season that runs from May to December annually and within spatial restrictions, while attempting to ensure a viable fishery, and since its implementation has achieved high compliance and reduced illegal poaching. Under this new management regime, some areas of the harbour designated as "bird sensitive areas" (BSA) for overwintering waders and waterfowl that had previously been closed to fishing activity were opened to clam dredging from 1st July to 31 st October. The changes in the management measures in the study area under the by-law are summarised in Table 1. Other bird sensitive areas in the harbour now remain closed to dredging all year round. Monitoring of impacts is critical within an adaptive management process, and the opening of these areas provided opportunity for the local fisheries authority to study the effects of pump-scoop dredging on littoral soft-sediment habitats and in relation to the new management measures.

The study area (Fig. 2) is a relatively sheltered intertidal channel of reduced salinity influenced by the Rivers Corfe and 


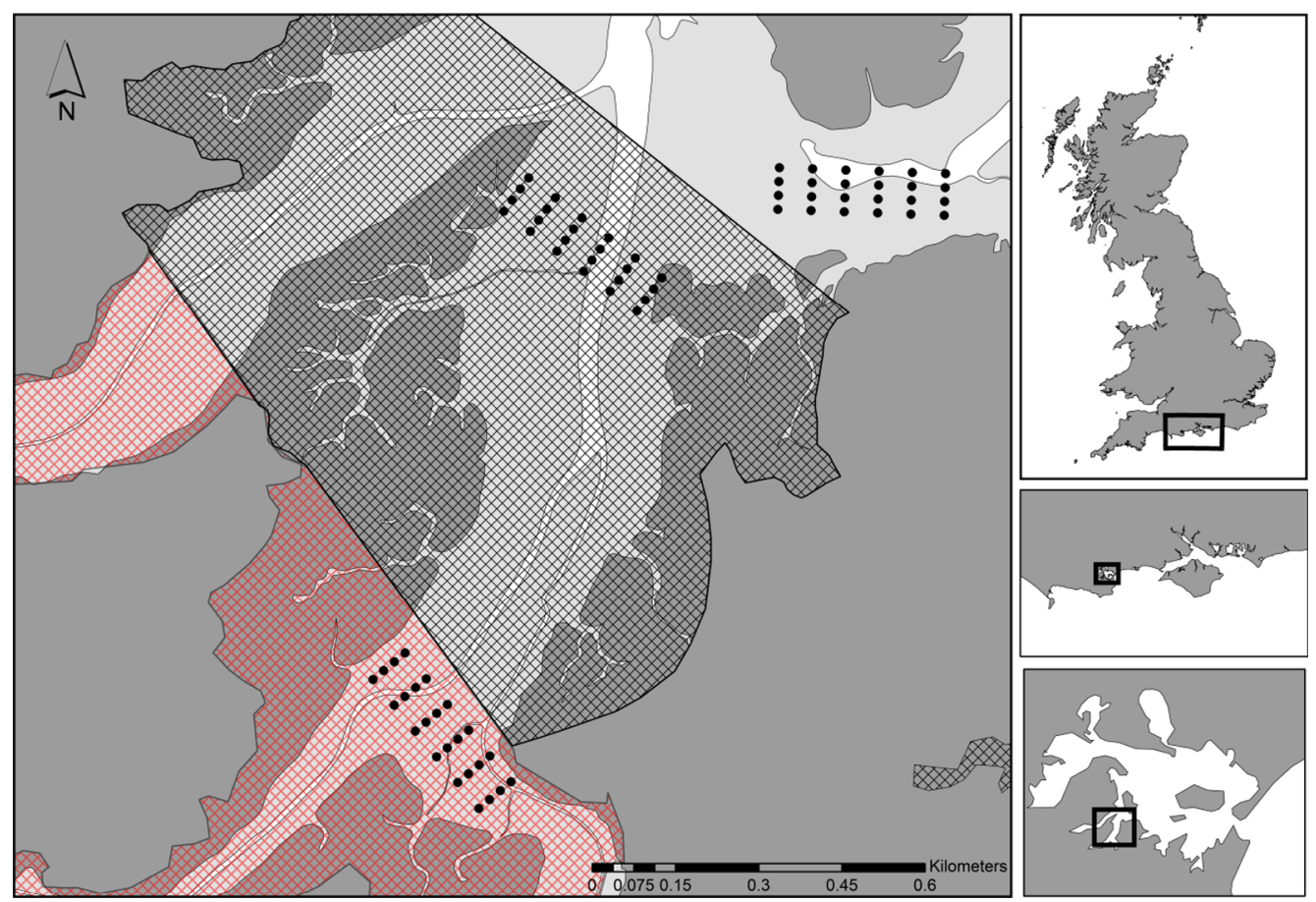

Fig. 2. The study area in Poole Harbour known as Wytch Lake, indicating the sampling stations visited in June and November, 2015. The Wytch Lake Bird Sensitive Area (BSA) is indicated by the hatching. The southern hatching represents the area closed to dredging (control) and the northern hatching represents the area open July 1-October 31st (newly opened, short-term dredging). The most northerly sampling grid outside of the hatching has historically been heavily fished. The southern tip of Round Island is indicated immediately north of the study site. Shellfish dredging is permitted outside of the BSA from 25th May-24th December. The location within Poole Harbour, the UK south coast and the UK is also indicated.

Table 1. Fishing intensity and seasonal openings of each site sampled under the dredge permit by-law, which came in to force on 1 st July 2015.

\begin{tabular}{lll}
\hline Site & Pre-by-law & Post-by-law \\
\hline Control & Closed & Closed \\
Newly opened & Closed & Open (1st July-31st October) \\
Heavy dredging & Open & Open (25th May-24th December) \\
\hline
\end{tabular}

Frome at the uppermost extent of the channel. Environmental data across the site was extracted from a validated tidal flow model of Poole Harbour that predicts environmental changes throughout the harbour over two spring and neap tide cycles (HR Wallingford, 2004; Herbert et al., 2012). Light Detection and Ranging (LiDAR) data indicate that elevation is within $0-2 \mathrm{~m}$ above chart datum throughout the study area. Existing bathymetric data used in the tidal flow model (HR Wallingford, 2004 ) indicate a range of $0.48 \mathrm{~m}$ in mean elevation (metres above chart datum) across the different dredge management areas within the study site. The site is of reduced salinity, with mean median salinity values extracted from the model within 27.3$27.4 \mathrm{ppt}$ across all dredge management areas. Mean maximum velocities range from 0.13 to $0.25 \mathrm{~m} / \mathrm{s}$ across the management areas.

The intertidal assemblages in this region of the harbour are largely dominated by the polychaete Hediste diversicolor and the bivalve Macoma balthica in littoral sandy mud (Herbert et al., 2010). The locations of each area are indicated in Figure 2. Although dredging occurs throughout the harbour (subject to spatial restrictions) this site was chosen for the study as it provides three areas under different management regimes in close proximity of one another, easily sampled within the time and budget constraints of the project.

\subsection{Sampling}

Sampling followed a before-after-control-impact (BACI) design, in relation to the four month open season within the BSA, which is widely used in assessing environmental impacts (Underwood, 1993). The design allows for the detection of any changes relative to spatial and temporal variation associated with the opening of the area to dredging. The magnitude of any effect relative to the control area is therefore of greatest interest.

This enabled a comparison of the impact of pump-scoop dredging in an area that had previously been closed (newly opened, short-term dredging) with the control site (low fishing effort) and heavily dredged (long-term, high fishing effort) areas (Tab. 1). A sampling grid was placed across each area 
that comprised 24 sampling points in a $6 \times 4$ rectangular design at $50 \mathrm{~m}$ intervals. As it is difficult to predict fishing distribution in a newly opened area, a grid design was employed to capture dredging pressure in the BSA. Core samples from each of the three sites (Fig. 2) were taken at high water from a local fishing vessel in June and November, 2015. At each location a single core of $10 \mathrm{~cm}$ diameter and $30 \mathrm{~cm}$ depth was taken for faunal analysis using a hand-held suction corer. This is a standard-diameter corer for use in intertidal environments that was designed to sample deeper than the usual $15 \mathrm{~cm}$ depth corers in order to better sample larger and deeper burrowing fauna. In the laboratory, samples were sieved through a $0.5 \mathrm{~mm}$ sieve and all macrofauna retained were preserved in 5\% formal buffered saline. Samples were then sorted, measured and identified to species level with the latest nomenclature according to the World Register of Marine Species (WoRMS, 2017: last accessed 7th November 2017).

\subsection{Measuring fishing effort}

Fishing intensity in each area was determined based on historic sightings data provided by the Southern Inshore Fisheries and Conservation Authority (SIFCA). Fishery officer observers recorded the presence of clam dredging and any other activity during the study period during weekly patrols (Tab. 1). At low tide (spring tide, LW 1325, Height $0.5 \mathrm{~m}$ ) on 23rd November 2015, after the closure of the BSA to dredging on the 31 st October, and with fishing continuing outside of the BSA boundary a DJI Phantom 3 Pro quad-copter Unmanned Aerial System (UAS) was flown over the study site to acquire vertical stereo aerial photographs (VSAP) of $3.5 \mathrm{~cm}$ resolution. This imagery was then used to map the level of sediment scarring in each area as a result of dredging. The aerial imagery was loaded into ArcMap 10.1 Geographic Information System (GIS) and image classification was undertaken to estimate the extent of dredge scarring in each management area as a measure of fishing intensity. Pixels were grouped into classes to represent scarred or unscarred sediment and the percentage of scarred sediment in each area was then calculated using the area of each pixel class.

\subsection{Sediment analysis}

A second core was taken from each sampling point in June and November, 2015 for sediment analysis. Each sample was homogenised across all sediment depths before a $10 \mathrm{~g}$ subsample was taken. Organic content was then measured by Loss on Ignition, placed in a muffle furnace at $450{ }^{\circ} \mathrm{C}$ for 12 h. A Malvern Mastersizer 3000 (Malvern, 2017) laser particle size analyser was then used to quantify sediment particle size from the same subsample, from which cumulative volume curves were produced and the \% volume of sand and silt calculated.

\subsection{Statistical analysis}

Data were analysed using the software PRIMER v6 (Anderson et al., 2008) and the vegan package within RStudio version 1.0.136. Univariate analysis of individual responses (i. e. sediment characteristics and species abundances) was carried out using two-factorial ANOVAs including site (i.e. treatment) and sampling time as fixed factors and an interaction term between the two. Any environmental effect of dredging in relation to the BACI sampling design (i.e. an indication of whether the magnitude of the temporal effect between sampling points differs between sites) was identified by significance of the interaction term. Where variances were heterogeneous ANOVA with White's adjustment for heteroscedasticity was used. In order to quantify the size of the effect, the Eta-squared value is reported, an effect size specifically used in ANOVA models that describes the amount of variation in the response variable attributable to a particular level of the predictor (Cohen, 1988). For individual species and overall community abundances, Hedges' $d$ was calculated to indicate the size of the effect (Cohen, 1988). This value is a standardised measure of the difference between groups and is more informative than $p$-values alone, with a value of zero indicating no effect (Borenstein et al., 2009).

Multivariate analysis was undertaken on a Bray-Curtis similarity matrix derived from $\log +1$ transformed species abundance data using PRIMER 6 and the vegan package in RStudio (Clarke and Gorley, 2006). This allows better assessment of changing dominance patterns rather than over-compensate the contribution of rarer species by using other coefficients or a simple presence/absence matrix (Clarke and Gorley, 2006). In order to identify similarities between the macrofaunal assemblages at different sampling points and sites CLUSTER and SIMPER (similarity percentages) analyses were undertaken. A PERMDISP (Clarke and Gorley, 2006) routine within PRIMER v6 was utilised to characterise the amount of dispersion within the multivariate dataset between sampling times and sites, as a potential indicator of environmental stress (i.e. as a result of fishing disturbance) (Warwick and Clarke, 1993). Permutational analysis of variance (PERMANOVA) was then undertaken with site and time included as fixed factors and an interaction term between the two, to identify differences in the overall community structure present between sampling sites and before or after the four month fishing period. By using permutations the PERMANOVA test is unaffected by correlation structures that may exist in the data (any correlation is destroyed through randomly shuffling samples) and is a powerful procedure in assessing changes in community structure in a variable environment (Anderson, 2001; Anderson et al., 2008; Anderson and Walsh, 2013). PERMANOVA was performed on untransformed data once homogeneity of variance had been identified. Environmental covariates were also included in the PERMANOVA analysis to investigate their influence on the community assemblage.

Canonical Analysis of Principal Coordinates (CAP) was carried out on the Bray-Curtis similarity matrix. CAP is a constrained ordination procedure that identifies axes through a multivariate cloud of data points. A discriminant CAP was used in this study. This method of CAP identifies axes that best discriminate between a priori groups, known as canonical discriminant analysis. Discriminant canonical analysis therefore allows the investigation of an a priori hypothesis to identify and characterise differences between groups, such as those identified as significant through PERMANOVA which may not be clearly visualised through MDS, and is a useful ordination technique for species abundance data (Anderson and Willis, 2003). 
Table 2. Fishing intensity in each area as represented by the number of Southern Inshore Fisheries and Conservation Authority (SIFCA) patrol sightings in each area during the 2015 season and the estimated disturbed area from image classification methods.

\begin{tabular}{llll}
\hline Site & Fishing intensity & No. sightings & Estimate disturbed sediment (\% area) \\
\hline Control & Low (none during study period) & 0 & 20.11 \\
Newly opened & Intermediate (short-term) & 11 & 68.03 \\
Heavy dredging & High (long-term) & 38 & 67.94 \\
\hline
\end{tabular}

Values for the AMBI (AZTI Marine Biotic Index) (Borja et al., 2000) and BO2A (Benthic Opportunist Annelids Amphipods) (Dauvin and Ruellet, 2009) biotic indices were calculated for each site across the study period. These values provide an indication of overall habitat quality. AMBI was developed to quantify the ecological quality of European coasts, providing a classification of pollution or disturbance levels in a site (Borja et al., 2000). BO2A represents the ratio between opportunistic species and sensitive species in estuarine environments (Dauvin and Ruellet, 2009) as a measure of benthic habitat quality used in ecological assessments. AMBI values were calculated using the BEQI2 package in the $\mathrm{R}$ software, and $\mathrm{BO} 2 \mathrm{~A}$ values were calculated as:

$$
\mathrm{BO} 2 \mathrm{~A}=\log _{10}\left[\left(f_{o a} / f_{s a}+1\right)+1\right],
$$

where $f_{o a}$ is the frequency of opportunistic annelids, Oligochaeta and Hirudinea within a sample, divided by the total abundance within the sample, and $f_{s a}$ is the frequency of amphipods, excluding opportunistic Jassa spp., divided by the total abundance in a sample (Dauvin et al., 2016).

\section{Results}

Since no Vessel Monitoring System (VMS) or logbook data from this fishery exists, the fishing intensities at each site during the study period were quantified by fisheries patrol sightings data (provided by SIFCA) and by aerial imagery obtained from the drone survey across the site. Results indicate that the extent of dredging in the newly opened and historically dredged sites is similar, but slightly higher in the new site (Tab. 2 ). Sightings are notably higher in the heavily dredged site despite similar estimates for both sites, which may be due to the infrequency of SIFCA patrols. The scarring identified in the control site through this method is considered to be due to the 2015 stock assessment that was carried out over a single day in May, 2015 by SIFCA in the area which used a local pump-scoop fisherman to sample clams in the area, as no sightings were observed by patrol officers throughout the study period and discussions with local fishermen indicated that this area was not fished commercially during the study period.

\subsection{Environmental factors}

Particle size distribution curves for each site in June and November are presented in Figure 3. Both organic content and volume of fine sediments decreased in all sites throughout the study period, with the largest reduction in each measure observed in the heavily dredged site (Tab. 3).
Two-factorial ANOVAs show a significant main effect of site $(F(2,138)=109.01, \quad p<0.001)$ and of time $(F$ $(1,138)=21.19, p<0.001)$ on the proportion of fine sediments $(\%$ volume $<0.63 \mu \mathrm{m})$. Tukey post-hoc tests indicated that a significant reduction in proportion of fine sediment was only found at the heavily dredged site throughout the study period. In both June and November, fine sediment content at this site was significantly lower than that at both the control site and newly opened site, while no difference was present between the newly opened and control sites. The interaction term is non-significant $(F(2,138)=2.82, p=0.06)$, with an eta-squared value of the interaction of 0.01 , indicating a small effect of dredging on the fine sediment content throughout the study period.

A slight reduction in sediment organic content was observed in all sites although this was largest in the heavily dredged site (Tab. 3; Fig. 3. A two-factorial ANOVA shows no significant effect of time $(F(1,138)=1.46, p=0.23)$ on the organic content of sediment, but a significant main effect of site $(F(2,138)=63.84, p<0.001)$. Tukey post-hoc testing indicates significantly less organic content at the heavily dredged site than both the newly dredged and control sites, which showed no difference. Results show no significant interaction term between the effect of site and time on organic content $(F(2,138)=0.51, p=0.60)$, with an eta-squared value of $<0.01$, indicating only a very slight effect (Cohen, 1988).

\subsection{Biological assemblage}

A total of 49 taxa (Supplementary Tab. S1) were identified in samples from June and November and the assemblages in the study area were similar to that found in the area during a previous, unrelated biotope survey across the whole harbour (Herbert et al., 2010). SIMPER analysis indicates that $H$. diversicolor, Tubificoides spp. and the bivalve $A$. tenuis dominate assemblages at all sites (Supplementary Tabs. S2-S4 (Online Resource 1)). Although $H$. diversicolor is the dominant species, abundance varied between treatments. The contribution of other species also differs between sites, with species within the order Actiniaria and the cirratulid $A$. marioni making the largest contribution to the similarity of samples across the heavily dredged site. Although species assemblages were similar across the newly opened and heavily dredged sites, species occurred in different abundances. Table S4 (Online Resource 1) indicates comparatively higher abundances of the polychaetes $H$. diversicolor and $A$. marioni at the heavily dredged site. In the nMDS plot derived from the Bray-Curtis similarity matrix clearer grouping of samples between sites taken in November, 2015 is apparent than in June (Fig. 4). Two plots based on June and November data separately are presented in Supplementary Material (Fig. S2) for clarity. 
a

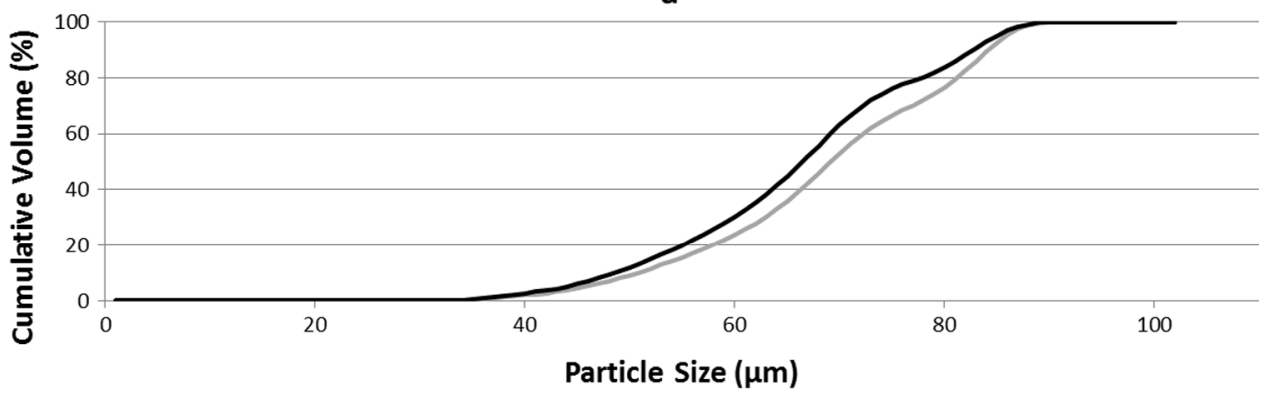

b

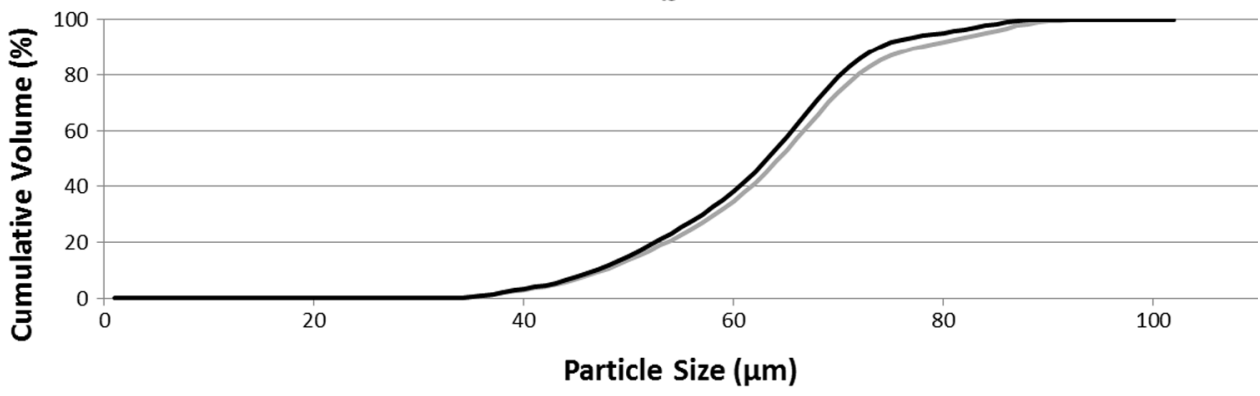

C

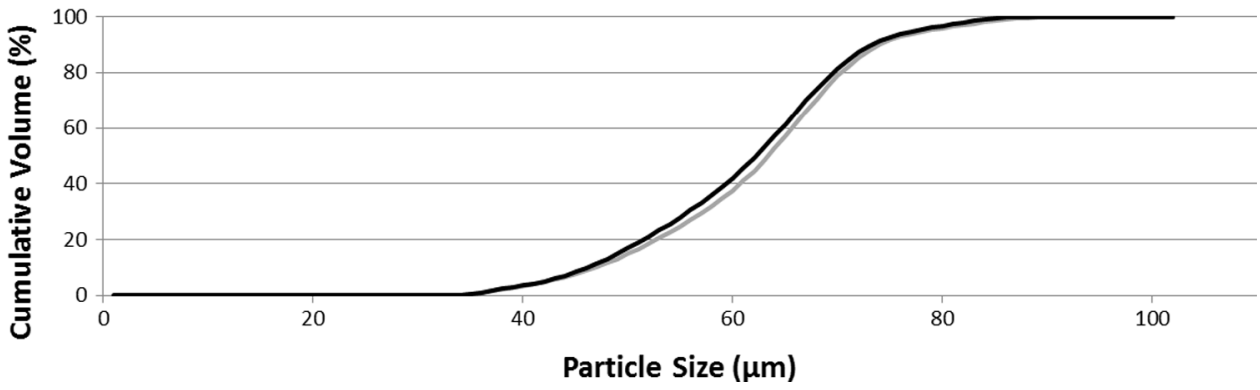

Fig. 3. Sediment particle size cumulative volume curves for each site in June and November 2015. (a) heavily dredged site; (b) newly dredged site; (c) control.

A test for homogeneity in the multivariate dispersions indicates no difference between groups $(p=0.90)$ and PERMANOVA was therefore considered appropriate and performed on untransformed data. Two-factorial PERMANOVA shows a significant main effect on the macrofaunal assemblage of both site and time (before and after fishing) (Tab. 4). Moreover a significant interaction between site and time indicates that the magnitude of the change in the overall assemblage throughout the study period varies between sites. The proportion of sandy sediment $(>0.63 \mu \mathrm{m})$ has a significant influence on the community structure, although no effect of organic content is evident. Proportion of fine sediments was removed from this analysis due to significant co-linearity with sand content.

Pairwise comparison shows that macrofaunal community structure differed significantly between sites both before and after dredging (Tab. 5). The magnitude of this difference appears to have changed however throughout the fishing period, as demonstrated by the interaction term. The $t$ statistics, representing the ratio of between- to within-group variability, indicate an increase in this difference between the control site and both the newly and heavily dredged sites, with a difference in the $t$-statistic between June and November of 0.82 and 0.97 at the newly and heavily dredged sites, respectively. The difference between the two dredged sites decreased however, with a reduction in the $t$-statistic of 0.23 between June and November, consistent with the clearer grouping in November in Figure 4 (and Fig. S2).

CAP was undertaken to characterise the distinctiveness of the differences identified through PERMANOVA more effectively than through MDS ordination, which indicated little notable grouping of samples (Anderson et al., 2008). CAP ordination shows clearer grouping between samples from the middle, newly dredged site between June and November (Fig. 5). Samples from this site from June are predominantly grouped together with control samples, while those from November show more variation. Overlaid species vectors indicate that samples from the heavily dredged site and to some extent the newly opened site obtained in November are characterised by higher abundances of polychaete and oligochaete worms, in particular capitellids, H. diversicolor, Tubificoides spp. and A. marioni. Samples from the control site however indicate a dominance of Peringia ulvae and A. tenuis. 
Table 3. Mean ( $\pm 95 \mathrm{CI}$ ) organic content (mass Loss On Ignition $(\mathrm{g}))$ and $\%$ volume sediment $<0.63 \mu \mathrm{m}$ across each site in June and November 2015. Significant changes throughout the study period are indicated in bold.

\begin{tabular}{llllr}
\hline Site & \multicolumn{2}{c}{ Organic content $(\mathrm{g})$} & \multicolumn{2}{c}{ Fine sediment $(\%)$} \\
\cline { 2 - 4 } & June & November & June & November \\
\hline Control & $6.39 \pm 1.08$ & $6.25 \pm 0.72$ & $83.25 \pm 3.30$ & $80.71 \pm 1.50$ \\
Newly opened & $5.71 \pm 0.66$ & $5.58 \pm 0.56$ & $81.20 \pm 2.30$ & $75.68 \pm 3.03$ \\
Heavy dredging & $3.19 \pm 0.39$ & $2.48 \pm 0.39$ & $\mathbf{6 4 . 8 7} \pm \mathbf{4 . 1 8}$ & $\mathbf{5 4 . 7 3} \pm \mathbf{4 . 6 7}$ \\
\hline
\end{tabular}

Table 4. Results of a two-factorial PERMANOVA on community abundance data across sites between June and November 2015 and including environmental covariates. d.f. $=$ degrees of freedom; S.S. = sum of squares; M.S. = mean squared.

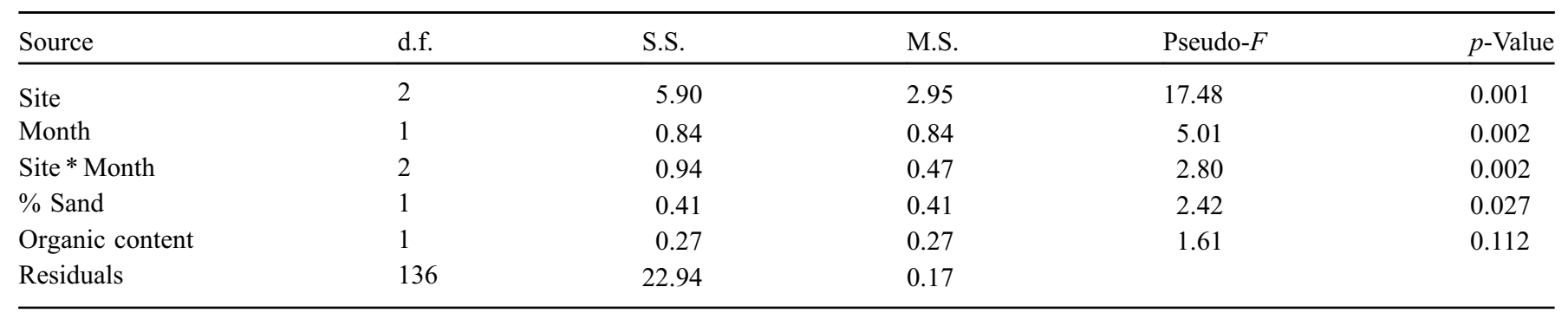

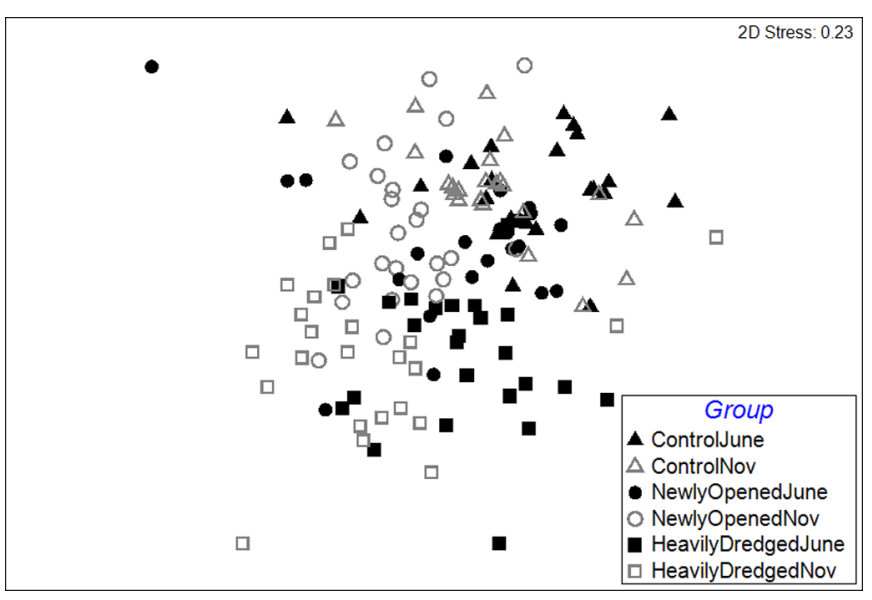

Fig. 4. Two-dimensional MDS plot derived from the $\log (x+1)$ transformed similarity matrix indicating the similarity between the macrofaunal assemblages at sampling locations in June (black) and November (grey) 2015. Circles=newly dredged site/medium dredging intensity (open July-October), squares = heavily dredged site, triangles $=$ control site.

CAP results indicate that the optimal number of $\mathrm{PCO}$ axes required to explain the highest proportion of variance in the data is $4(m=4)$. This explains $63.9 \%$ of variation within the data, with $59.03 \%$ of samples correctly classified (i.e. classified into the correct group based on the data).

The overall structure of the benthic assemblage at the site newly opened to dredging appears therefore to have shifted further from resembling the control site towards conditions similar to those at the heavily dredged site during the study period. SIMPER analysis identified those species contributing most to the difference at each site between June and November 2015 (Supplementary Tabs. S5-S7). Most species demonstrate an increase in abundance between June and November, regardless of site. At the newly dredged site, notable increases of $H$. diversicolor and A. marioni are evident (Fig. 6), and ANOVA showed significant interaction terms for both these species (Tab. 6). In comparison to the other sites, A. marioni was largely absent from the control site and showed a lesser increase at the heavily dredged site, while densities of $H$. diversicolor remained relatively stable at both the control and heavily dredged sites throughout the study period, although more than doubled in the site newly opened. These increases in $H$. diversicolor largely represent increases in smaller $(<10 \mathrm{~mm})$ individuals. Throughout the study period the proportion of this size class increased on average from 27 $55 \%$ and from 11 to $58 \%$ of all $H$. diversicolor in samples from the newly and heavily dredged sites respectively. No such trend is evident at the control site where the relative proportions of each size group appeared stable $(18 \%$ and $19 \%$ in June and November, respectively).

Densities of the spionid Streblospio shrubsolii also increased dramatically at the newly dredged site compared to the other sites. In contrast, densities of the molluscs $A$. tenuis and $P$. ulvae decreased at both the dredged sites, compared to increases at the control site. The reduction of $A$. tenuis was largest at the heavily dredged site (Fig. 6), and a significant ANOVA interaction term was evident found for this species (Tab. 6). Densities of all species are generally much lower at the control site, which appear more stable throughout the study period than at the two dredged sites, at which the magnitude of the change is much larger.

The size of the effect (Hedges' $d$ ) in changes in abundance for each species at both the newly and heavily dredged sites shows a positive effect of fishing on the abundance of all 

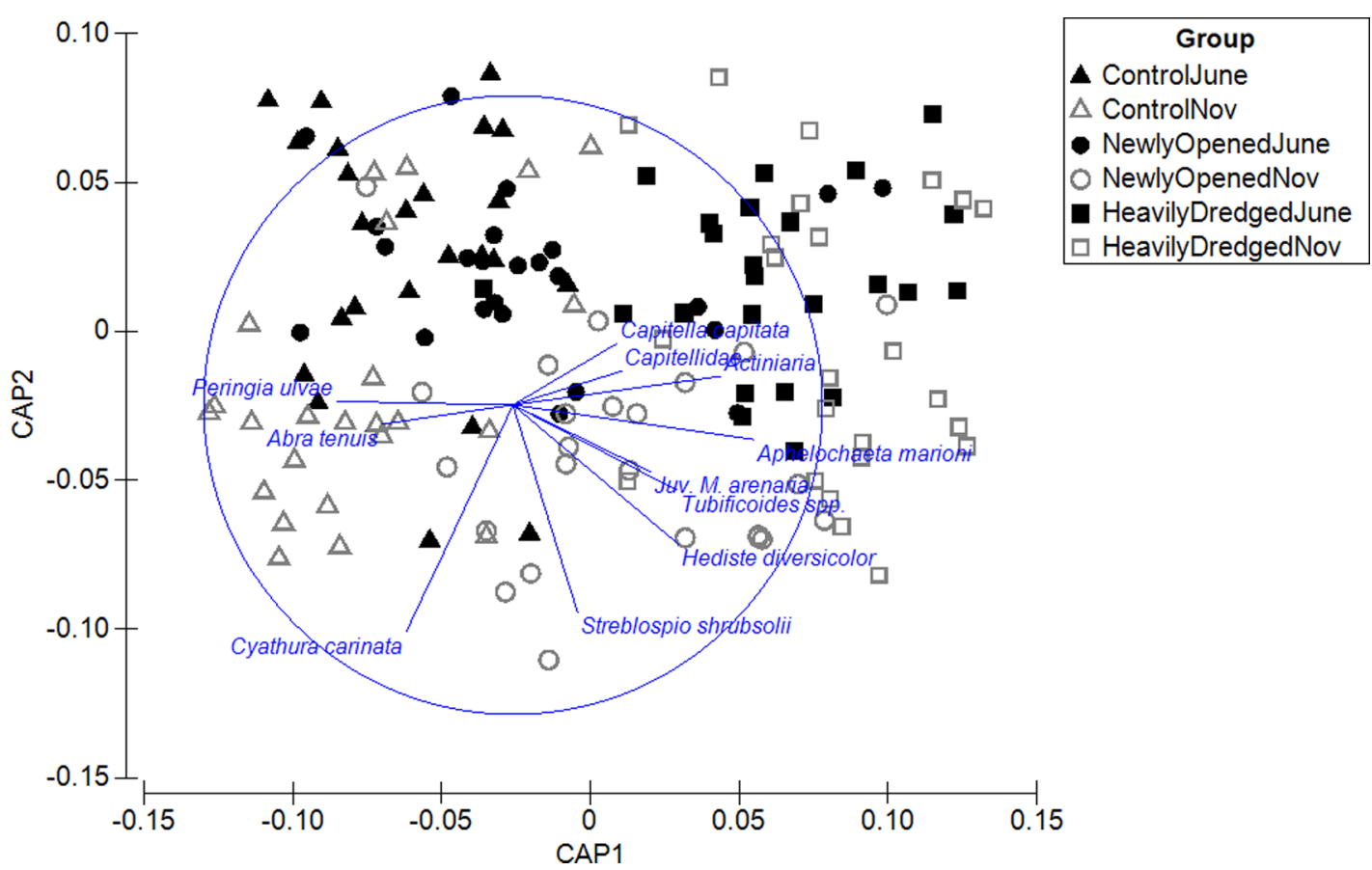

Fig. 5. Canonical ordination for the discriminant analysis of square-root transformed species abundance data. Spearman rank correlations of individual species abundance are overlaid (restricted to those with vector lengths $<0.4$ ). Black symbols $=$ June 2015 ; grey symbols $=$ November 2015. Circles = newly dredged site (open July-October), squares=heavily dredged site (historically dredged, open all season), triangles $=$ control site.

Table 5. Results of pairwise comparison of macrofaunal assemblage between sites in June and November 2015 following the PERMANOVA analysis.

\begin{tabular}{llll}
\hline Comparison & Month & $t$-Statistic & $p$-Value \\
\hline Control site: Newly opened & June & 2.3895 & 0.0001 \\
Control site: Heavy dredging & June & 3.9779 & 0.0001 \\
Newly opened: Heavy dredging & June & 2.6697 & 0.0001 \\
Control site: Newly opened & November & 3.206 & 0.0001 \\
Control site: Heavy dredging & November & 4.9506 & 0.0001 \\
Newly opened: Heavy dredging & November & 2.4434 & 0.0001 \\
\hline
\end{tabular}

species except $A$. tenuis and $P$. ulvae, with the largest change evident in the increase of $H$. diversicolor at the newly dredged site (Tab. 7).

\subsection{Community descriptors and habitat quality}

Diversity indices indicate a significant main effect of site $(F(2,138)=13.161, p<0.001)$ on species richness across both months, with a significantly higher number of species occurring in samples from the dredged sites compared to the control site (Tab. 8). A significant main effect of month $(F$ $(1,138)=14.99, \quad p<0.001)$ was also observed, although pairwise comparisons indicate that this increase was only significant in the site newly opened. The interaction term however was non-significant $(F(2,138)=1.30, p=0.27)$.

Simpson indices, which provide a measure of dominance within assemblages, were similar across sites with only a slight but non-significant change apparent over the study period in the heavily dredged site (Tab. 8).

Results show a significant main effect of site $(F$ $(2,138)=3.19, p<0.05)$ and time $(F(1,138)=7.30, p<0.01)$ on Shannon-Wiener indices, with an increasing trend apparent from the control site at the upper reaches of the creek to the outer, heavily dredged site (Tab. 8). A post-hoc Tukey test indicates that mean Shannon-Wiener values differ significantly between the site newly open to dredging in November and the control site in June. No significant interaction was observed $(F$ $(2,138)=1.35, p=0.26)$.

Two-factorial ANOVA shows a significant effect of both site $(F(2,138)=28.21, p<0.001)$ and time $(F(1,138)=15.68$, $p<0.001)$ on the total number of individuals found in samples (Fig. 7). The interaction term of the model was non-significant $(F(2,138)=1.90, p=0.15)$. Pairwise comparisons however indicate a significant increase in the total number of individuals 

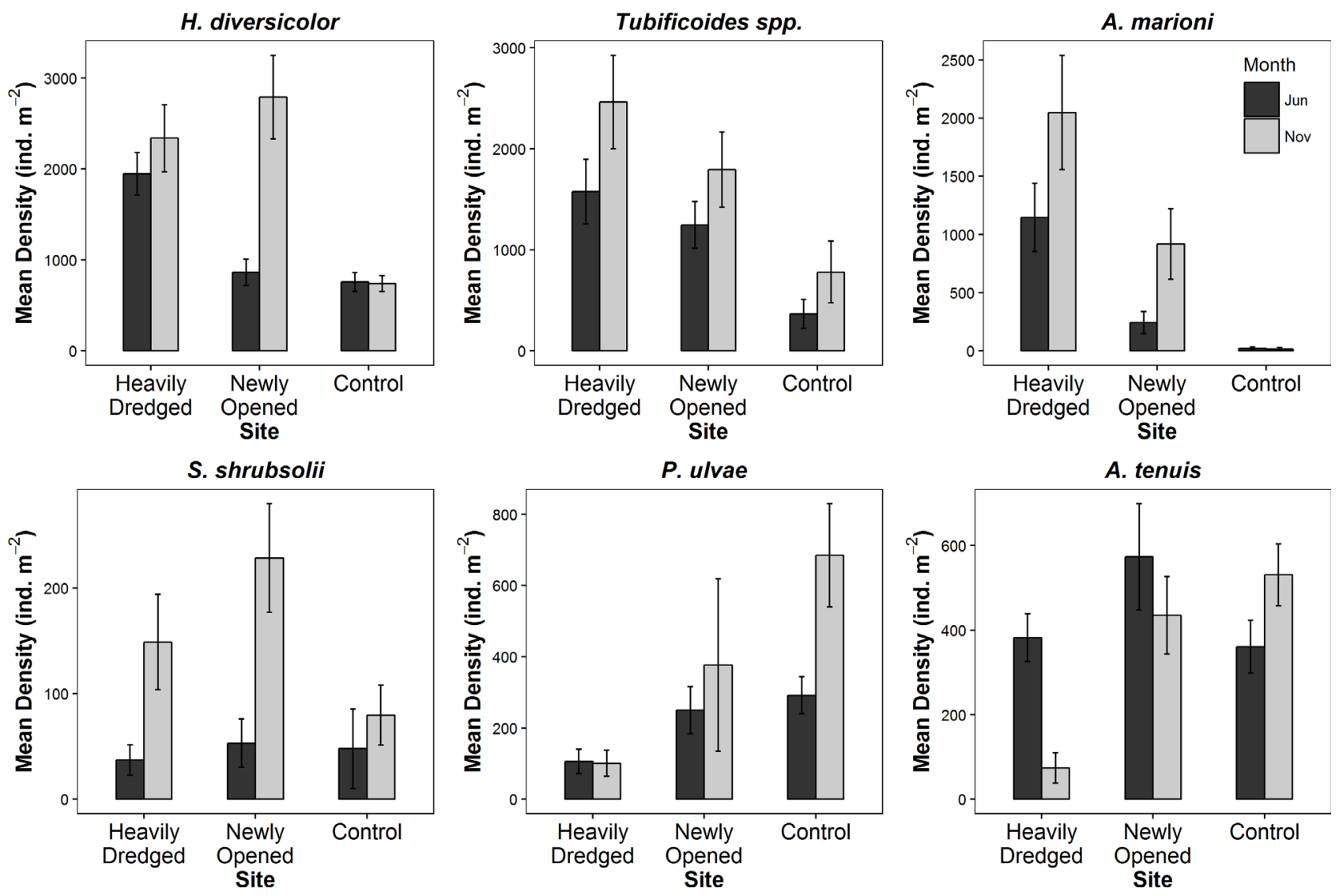

Fig. 6. Mean ( \pm S.E.) densities of common species in June (dark grey bars) and November (light grey bars) 2015 at each site. H. diversicolor (Phyllodocidae), Tubificoides spp. (Tubificidae), A. marioni (Cirratulidae), S. shrubsolii (Spionidae), P. ulvae (Hydrobiidae), A. tenuis (Semelidae).

Table 6. ANOVA results for individual species abundance across the study period and between sites.

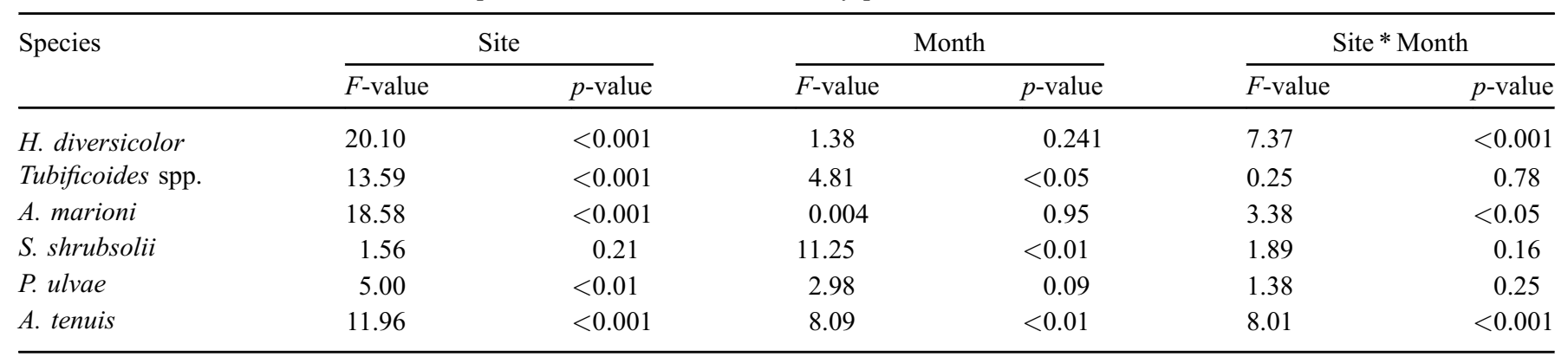

at the newly dredged site, while no such difference was observed at the control or heavily dredged sites. Total number of individuals was significantly higher at the heavily dredged site than at the control site across the study period. By November the total abundance had increased at the site newly opened and was now similar to the heavily dredged site and significantly higher than at the control site.

Biotic indices indicate site differences in both AMBI $(F$ $(2,138)=11.94, \quad p<0.001)$ and $\mathrm{BO} 2 \mathrm{~A} \quad(F(2,138)=29.43$, $p<0.001)$ values, although no significant effect of month or the interaction term. Despite significant site differences in the AMBI values, all sites are classed as "moderately disturbed"
(Borja et al., 2000). BO2A results indicate that at both sampling times the control site and the newly dredged site are of "good" quality, while the heavily dredged site is of "moderate" quality (Dauvin and Ruellet, 2009) (Tab. 8).

\section{Discussion}

This study assessed the impacts of a novel pump-scoop dredge for which data is currently lacking. In the strictest sense, the sampling design used in this study is not fully replicated, although while the BACI design lacks replication of treatments, with inherent issues of pseudoreplication 
Table 7. Standardised mean differences in abundance of each species plus total number of individuals at newly and heavily dredged sites, compared to control conditions across both sampling times.

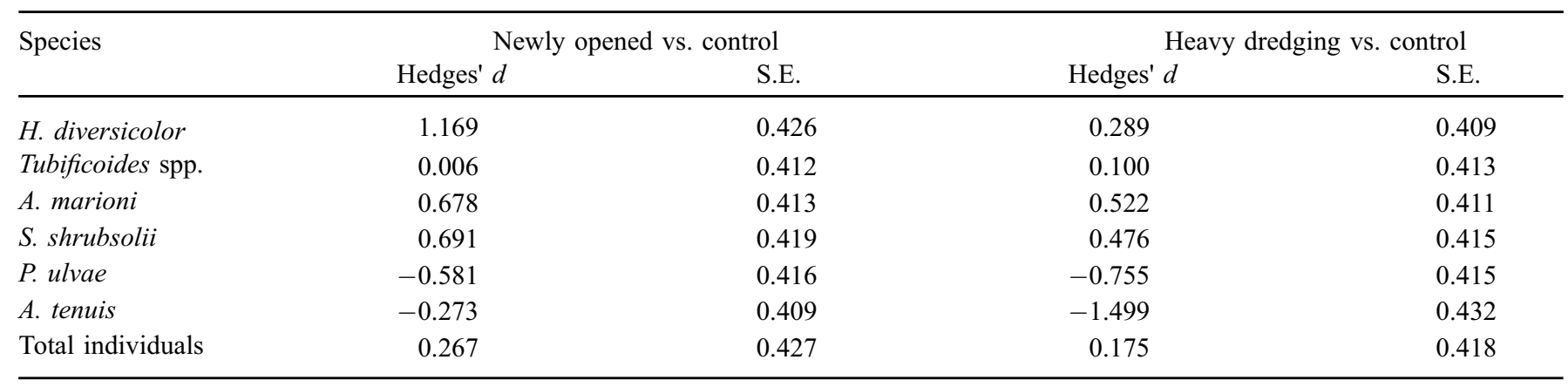

Table 8. Mean ( $\pm 95 \%$ C.I.) diversity and biotic indices (AMBI: AZTI Marine Biotic Index; BO2A: Benthic Opportunistic Annelid Amphipods) for each site in June and November 2015. Significant changes over time are highlighted in bold. Thresholds for each biotic indices are included below.

\begin{tabular}{|c|c|c|c|c|c|c|c|c|c|c|}
\hline Site & \multicolumn{2}{|c|}{ Species richness } & \multicolumn{2}{|c|}{ Simpson } & \multicolumn{2}{|c|}{ Shannon-Wiener } & \multicolumn{2}{|c|}{ AMBI } & \multicolumn{2}{|c|}{$\mathrm{BO} 2 \mathrm{~A}$} \\
\hline Control & $5.33 \pm 0.71$ & $6.29 \pm 0.60$ & $0.87 \pm 0.22$ & $0.88 \pm 0.02$ & $1.56 \pm 0.13$ & $1.73 \pm 0.10$ & $3.36 \pm 0.24$ & $3.52 \pm 0.24$ & $0.05 \pm 0.02$ & $0.06 \pm 0.02$ \\
\hline Newly Opened & $5.83 \pm 0.79$ & $7.88 \pm 0.88$ & $0.86 \pm 0.02$ & $0.87 \pm 0.02$ & $1.63 \pm 0.12$ & $1.87 \pm 0.12$ & $4.02 \pm 0.25$ & $3.81 \pm 0.24$ & $0.12 \pm 0.06$ & $0.11 \pm 0.04$ \\
\hline Heavy Dredging & $7.33 \pm 0.75$ & $8.13 \pm 1.29$ & $0.86 \pm 0.03$ & $0.84 \pm 0.08$ & $1.80 \pm 0.12$ & $1.83 \pm 0.21$ & $4.06 \pm 0.27$ & $4.01 \pm 0.27$ & $0.16 \pm 0.06$ & $0.16 \pm 0.06$ \\
\hline
\end{tabular}

AMBI Disturbance Thresholds: $<1.2=$ undisturbed; $1.2 \leq 3.3=$ slightly disturbed; $3.3 \leq 5.0=$ moderately disturbed; $5.0 \leq 6.0=$ heavily disturbed; $6.0 \leq 7.0=$ extremely disturbed.

BO2A Quality Status: $<0.025=$ high; $0.025-0.130=$ good; $0.130-0.199=$ moderate; $0.199-0.255=$ poor, $>0.255=$ bad.

and distinguishing site vs. treatment differences, it was the most appropriate option within an established and operational fishery with limited resources available for the study. A grid design was considered likely to best capture any fishing effort in the newly opened area, which is hard to predict. While other sampling designs may be more effective in reducing uncontrolled variability and distinguishing treatment differences over site differences (Cotter et al., 1997), the BACI design allows for changes due to dredging to be identified while accounting for natural spatial and temporal variability.

PERMANOVA results show site differences in the benthic community structure before the opening of the 2015 dredge season. No gradient in salinity exists across sites, and given the significant effect of sand content on community structure this is likely driven by the gradient in sediment type from the southerly reaches of the creek to the lower dredged areas where conditions are sandier.

Accurate data on fishing intensity of inshore vessels less than $12 \mathrm{~m}$ is hard to obtain due to a lack of VMS data and a fishermen's logbook program tailored to the fishery. While our data only provides estimates of fishing intensity derived from SIFCA patrols and image analysis, following discussions with fishery officers and fishermen, we are confident that it accurately represents the distribution and relative intensity of fishing in the study area. Results of the aerial imagery analysis show the newly opened site was subject to heavy dredging comparable to the site that has been historically dredged, and over the course of the first season, the community structure in the newly opened site shifted significantly from conditions that were initially similar to the control site to those comparable to the site under heavy fishing pressure. Results indicate that this change was characterised by an increase in the abundance of marine worms, particularly $H$. diversicolor and $A$. marioni, but a decrease in abundance of the bivalve $A$. tenuis, for which the interaction terms of the ANOVAs were all significant. Despite the significant change in community structure at the newly opened site, no change in the biotope or ecological quality of either of the dredged sites was identified. BO2A values however show the site subject to previous dredging is of poorer quality, indicating relatively higher abundances of opportunistic species within Polychaeta and Oligochaeta, such as those that increased most dramatically throughout the study period at the newly dredged site and demonstrated a significant interaction term.

Such opportunists colonise disturbed areas through rapid dispersal and high reproductive rates (Grassle and Sanders, 1973; Grassle, 1974; Diaz-Castañeda et al., 1993), and may demonstrate large-scale spatial and temporal fluctuations in response to environmental changes (Grassle and Sanders, 1973; Grassle, 1974; Pearson and Rosenberg, 1978; Fauchald and Jumars, 1979; Bridges et al., 1994; Rossi and Lardicci, 2002; Dean, 2008). The observed increases in these groups are consistent with past studies following environmental or physical disturbance (Thistle, 1981; Sardá and Martin, 1993; Hall and Harding, 1997; Lardicci et al., 1997; 


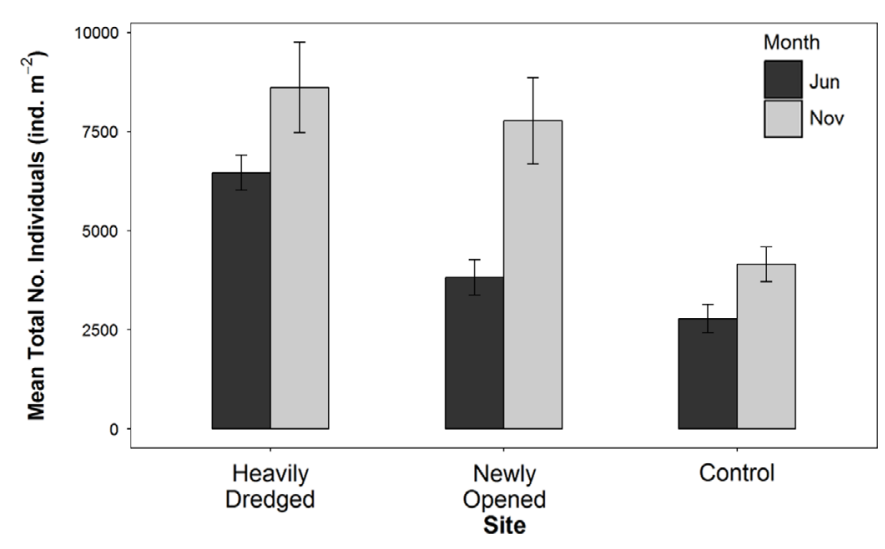

Fig. 7. Mean ( \pm S.E.) total number of individuals per $\mathrm{m}^{2}$ observed in samples from each site in June (dark grey bars) and November (light grey bars) 2015 .

Spencer et al., 1998; Chainho et al., 2006). Cesar (2003) observed similarly large increase in abundances of tubificid oligochaetes and polychaetes $A$. marioni, Polydora coliata and Phyllodoce malcatula in the area around Round Island in the proximity of the study area (Fig. 2) following six weeks of pump-scoop dredging, along with increases in $H$. diversicolor as observed in this study.

Clearly, seasonal changes in species abundances are evident throughout the study period. In many species, spawning and recruitment occurs throughout the summer months and into autumn when peaks in abundance may be observed (George, 1964; Scaps, 2002; Rossi and Lardicci, $2002)$, and the proportion of small $(<10 \mathrm{~mm}) H$. diversicolor in samples did increase in November 2015. Many of these recruits may be lost by the following spring however due to natural mortality throughout winter (Buchanan et al., 1978; Gray, 1981). The BACI design allows for assessment of changes relative to such temporal variation however, and overall the biological changes observed were largest in the site newly subjected to dredging disturbance, the only site at which significant increases in species richness and total abundance were observed; not dissimilar to changes observed following the use of other dredge gears (Hall and Harding, 1997). This perhaps indicates preferential settlement of $H$. diversicolor and $A$. marioni in this newly disturbed area following dredging, in the absence of larger individuals and adults that reduces competition for space and food (Caswell and Cohen, 1991). H. diversicolor is a scavenger species and may therefore benefit in the short-term from dredging disturbance (Britton and Morton, 1994). It has been suggested that benthic disturbance itself may actually stimulate reproduction in infaunal species (Barry, 1989), allowing species to utilise newly available patches and resources previously exploited by the dominant species in an area (Thistle, 1981; Pickett and White, 1985).

Physical disturbance is generally considered to reduce habitat heterogeneity and three-dimensional complexity (Auster et al., 1996; Thrush et al., 1998), although results are complicated by the different scales at which impacts occur. Locally, in low-energy, soft sediment environments such as the study area where high amounts of organic content and fine sediment occur, intermediate physical disturbance may increase habitat heterogeneity (Levin and Whitfield, 1994), promoting sediment oxygenation and turnover and perhaps facilitating juvenile settlement and an influx of species. Physiological stress due to a shallow redox layer may inhibit organisms' ability to occupy such sediments, perhaps evident in the lower levels of diversity and species abundances seen towards the more sheltered reaches of the study area in the control site, where higher levels of organic content and anoxic sediment were observed. McIlquham (unpubl.) postulated that this may be the reason for an observed increased diversity in some areas of Poole Harbour subjected to heavy pump-scoop dredging for clams and cockles.

Body size plays an important role in defining and detecting the magnitude of a species response to disturbance (Sanders et al., 2007), and the observed changes are largely in smallbodied fauna that respond rapidly to environmental fluctuations (Levin and Paine, 1974; Pearson and Rosenberg, 1978; Bridges et al., 1994; Rossi and Lardicci, 2002; Dean, 2008). While core sampling may under-sample larger species that are likely to be most affected by bottom-fishing (Lindeboom and de Groot, 1998; Bergman and van Santbrink, 2000), including the target species of the fishery, it is known that larger and longer-lived species, particularly worms are currently rare in Poole Harbour (Herbert et al., 2010). Furthermore, the shallow depth at which the pump-scoop dredge penetrates the sediment means that larger and deeper-burrowing species may be less likely to be affected by fishing.

Those species demonstrating a decline throughout the study (A. tenuis and P. ulvae) are small and relatively fragile molluscs that may suffer mortality from interaction with fishing gear and were the only species to demonstrate a reduction in abundance relative to the control site. A complete absence of epifaunal mollusc species and a significant reduction in the abundance of $A$. tenuis following mechanical dredging have been reported from nearby Langstone Harbour on the south coast of England (Southern Science, 1998). Bivalve molluscs such as A. tenuis comprise key prey items for molluscivorous shorebirds (Goss-Custard et al., 2006) and managers must consider implications on the SPA and BSA designations in Poole, although monitoring may be necessary to investigate long-term impacts and recovery.

No impact on the organic content was observed throughout the study period, although fine sediments were significantly reduced at the heavily dredged site. Bottomtowed fishing gear can result in a significant sediment plume (Ferré et al., 2008; O'Neill and Summerbell, 2011; Bradshaw et al., 2012; Palanques et al., 2014; Martín et al., 2015), which can contribute to the loss of organic content and finer sediment (Mayer et al., 1991; Schwinghamer et al., 1998). Both organic content and the volume of fine sediments were lower in the heavily dredged site, perhaps reflecting the higher intensity of fishing or a more dynamic environment where coarser sediments dominate. It is uncertain whether dredging caused the observed loss of fine sediments, and past studies have found no effect of pump-scoop dredging on sediment composition in Poole (McIlquham, unpubl.). Longterm or chronic fishing can nonetheless cause permanent shifts in habitat characteristics and community structure (Pauly, 1995; Handley et al., 2014), with implications for 
settlement and recruitment patterns (Wilson, 1990; Pinedo et al., 2000; Sebesvari et al., 2006). No significant change in sediment composition was evident at the site where settlement appeared the greatest however.

As mentioned, despite the changes identified no largescale shift in the overall biotope at the study sites has occurred between sampling events (Herbert et al., 2010) and there has been no change in habitat quality. Most species present are small-bodied and likely to pass through the dredge unharmed, and demonstrate natural fluctuations in abundance throughout the year (Grassle, 1974; Pearson and Rosenberg, 1978; Bridges et al., 1994; Rossi and Lardicci, 2002; Dean, 2008). Assessments carried out by fisheries and environmental managers often monitor and assess the condition of marine ecosystems and habitats in relation to high-level targets and indicators in response to anthropogenic pressures, and are subsequently more concerned with shifts in habitat or biotope type larger than those observed. Under the European Marine Strategy Framework Directive (MSFD) environmental managers work towards maintaining favourable conservation status and achieving "Good Environmental Status". Given that fisheries managers are increasingly attempting ecological risk management processes to fishing activities (Gibbs and Browman, 2015), the observed short-term changes may be of low concern to regulators and managers. Regular and longterm disturbance of this kind however may cause a permanent regime shift in community structure (Kraberg et al., 2011) and more chronic reduction in abundances of bivalve molluscs (Piersma et al., 2001), of which a number of species are present across the three sites.

It is recognised that recovery trends following fishing disturbance are an important consideration, which can vary according to the scale and intensity of the disturbance (Collie et al., 2000; Kaiser et al., 2006). Sampling following fishing disturbance was only undertaken once and due to the length of the season it is difficult to be certain when the last fishing disturbance took place within the study area. Clearly, changes have occurred in the BSA that coincide with its opening to short-term dredging, although evidence of the longevity and persistence of these changes is lacking, demonstrating the importance of continuous monitoring to inform adaptive management.

The Manila clam is spreading to other estuaries along the south coast of England and throughout Europe (Herbert et al., 2012; Humphreys et al., 2015; Chiesa et al., 2017) which is likely to tempt fisherman to exploit populations with these or other novel gears. Fisheries managers must be vigilant with regards to the development of novel gears, particularly when incentivised by the introduction of commercially harvestable non-native species. Adaptive management should also evaluate monitoring methods to determine impacts within these environmentally sensitive habitats.

\section{Supplementary Material}

Species lists and outputs from SIMPER and ANOSIM analyses for each site individually are available as Online Resource 1.

The Supplementary Material is available at http://www.alrjournal.org/10.1051/alr/2017044/olm.
Acknowledgements. The authors would like to acknowledge the support provided for this project and the wider $\mathrm{PhD}$ project by staff from the Southern Inshore Fisheries and Conservation Authority and Natural England. Thanks are also owed to David Bailey, a local Poole Harbour fisherman who assisted with sampling, and Andy Ford and Ross Hill of Bournemouth University for their assistance during remote sensing work.

\section{References}

Adams A, Reeve L. The Zoology of the Voyage of HMS Samarang, Mollusca, London, 1850, pp. 87

Anderson MJ. 2001. A new method for non-parametric multivariate analysis of variance. Austral Ecol 26: 32-46.

Anderson MJ, Walsh DC. 2013. PERMANOVA, ANOSIM, and the Mantel test in the face of heterogeneous dispersions: what null hypothesis are you testing? Ecol Monogr 83: 557-574.

Anderson MJ, Willis TJ. 2003. Canonical analysis of principal coordinates: a useful method of constrained ordination for ecology. Ecology 84: 511-525.

Anderson M, Gorley RN, et al. Permanova+ for Primer: Guide to Software and Statistical Methods, 2008.

Auster PJ, Malatesta RJ, et al. 1996. The impacts of mobile fishing gear on seafloor habitats in the Gulf of Maine (Northwest Atlantic): implications for conservation of fish populations. Rev Fish Sci 4: 185-202.

Barry JP. 1989. Reproductive response of a marine annelid to winter storms: an analog to fire adaptation in plants? Mar Ecol Prog Ser 54: 99-107.

Bax N, Williamson A, et al. 2003. Marine invasive alien species: a threat to global biodiversity. Mar policy 27: 313-323.

Beck F, Pezy JP, et al. 2015. Effects of clam rake harvesting on the intertidal Ruditapes habitat of the English Channel. ICES J Mar Sci 72: 2663-2673.

Bergman M, van Santbrink J. Fishing mortality of populations of megafauna in sandy sediments, in: M.J. Kaiser, S.J. de Groot (eds.), Effects of fishing on non-target species and habitats, Blackwell Science, Oxford, 2000, pp. 49-68.

Borja A, Franco J, et al. 2000. A marine biotic index to establish the ecological quality of soft-bottom benthos within European estuarine and coastal environments. Mar Pollut Bull 40: 11001114.

Borenstein MJ, Hedges LV, et al. Introduction to meta-analysis, John Wiley and Sons, Ltd., New York, 2009.

Bradshaw C, Tjensvoll I, et al. 2012. Bottom trawling resuspends sediment and releases bioavailable contaminants in a polluted fjord. Environ Pollut 170: 232-241.

Bridges TS, Levin LA, et al. 1994. Effects of sediment amended with sewage, algae, or hydrocarbons on growth and reproduction in two opportunistic polychaetes. J Exp Mar Biol Ecol 177: 99-119.

Britton W. Clam Cultivation Manual - No. 8. A special publication of Aquaculture explained in conjunction with Taighde Teo, 1991.

Britton JC, Morton B. 1994. Marine Carrion and Scavengers. Oceanogr Mar Biol Ann Rev 32: 369-434.

Buchanan J, Sheader M, et al. 1978. Sources of variability in the benthic macrofauna off the south Northumberland coast, 19711976. J Mar Biol Assoc UK 58: 191-209.

Caswell H, Cohen JE. 1991. Disturbance, interspecific interaction and diversity in metapopulations. Biol J Linn Soc 42: 193-218.

Cesar CP. 2003. The impact of clam fishing techiques on the infauna of Poole Harbour, in: Dissertation Submitted in Partial Fulfilment 
of the Requirements for the Degree of MSc (Oceanography), School of Earth and Ocean Science, University of Southampton.

Chainho P, Costa J, et al. Seasonal and spatial patterns of distribution of subtidal benthic invertebrate communities in the Mondego River, Portugal - a poikilohaline estuary. Marine Biodiversity, Springer, 2006, pp. 59-74.

Chiesa S, Lucentini L, et al. 2017. A history of invasion: COI phylogeny of Manila clam Ruditapes philippinarum in Europe. Fish Res 186: 25-35.

Clarke KR, Gorley RN. PRIMERv6: User Manual/Tutorial. PRIMER-E: Plymouth, 2006.

Cohen J. Statistical power analysis for the behavioral sciences, Lawrence Earlbaum Associates, Hillsdale, New Jersey, 1988, pp. 20-26.

Collie JS, Hall SJ, et al. A quantitative analysis of fishing impacts on shelf-sea benthos, British Ecological Society, 2000, p. 785.

Cotter A, Walker P, et al. 1997. Trial of a tractor dredger for cockles in Burry Inlet, South Wales. ICES J Mar Sci: J Cons 54: 72-83.

Dauvin JC, Ruellet T. 2009. The estuarine quality paradox: is it possible to define an ecological quality status for specific modified and naturally stressed estuarine ecosystems? Mar Pollut Bull 59: 38-47.

Dauvin JC, Andrade H, et al. 2016. Polychaete/amphipod ratios: an approach to validating simple benthic indicators. Ecol Indic 63: 89-99.

Dayton PK, Thrush SF, et al. 1995. Environmental effects of marine fishing. Aquat Conserv: Mar Freshw Ecosyst 5: 205-232.

Dean HK. 2008. The use of polychaetes (Annelida) as indicator species of marine pollution: a review. Rev Biol Trop 56: 11-38.

Diaz-Castañeda V, Frontier S, et al. 1993. Experimental reestablishment of a soft bottom community: utilization of multivariate analyses to characterize different benthic recruitments. Estuar Coast Shelf Sci 37: 387-402.

Fauchald K, Jumars PA. The diet of worms: a study of polychaete feeding guilds, Aberdeen University Press, 1979.

Fearnley H, Cruickshanks K, et al. The effect of bait harvesting on bird distribution and foraging behaviour in Poole Harbour SPA. Unpublished report by Footprint Ecology for Natural England, 2013.

Ferré B, de Madron XD, et al. 2008. Impact of natural (waves and currents) and anthropogenic (trawl) resuspension on the export of particulate matter to the open ocean: application to the Gulf of Lion (NW Mediterranean). Cont Shelf Res 28: 2071-2091.

Franklin DJ, Humphreys J, et al. An investigation into the annual cycle of phytoplankton abundance in Poole Harbour and its relationship with Manila clam nutrition, Report for the Marine Management Organisation, 2012.

George J. 1964. The life history of the cirratulid worm, Cirriformia tentaculata, on an intertidal mudflat. JMar Biol Assoc UK 44: 47-65.

Gibbs MT, Browman HI. 2015. Risk assessment and risk management: a primer for marine scientists. ICES J Mar Sci: J Cons 232.

Goss-Custard JD, West AD, et al. 2006. Intake rates and the functional response in shorebirds (Charadriiformes) eating macro-invertebrates. Biol Rev 81: pp. 501-529.

Grassle J. 1974. Opportunistic life histories and genetic systems in marine benthic polychaetes. J Mar Res 32: 253-284.

Grassle JF, Sanders HL. 1973. Life histories and the role of disturbance. Deep-Sea Res 20: 643-659.

Gray J. The Ecology of Marine Sediments: An Introduction to the Structure and Function of Marine Sediments. Cambridge Studies in Modern Biology, Vol. 2, 1981.
Hall SJ, Harding MJ. 1997. Physical disturbance and marine benthic communities: the effects of mechanical harvesting of cockles on non-target benthic infauna. J Appl Ecol: 497-517.

Handley SJ, Willis TJ, et al. 2014. The importance of benchmarking habitat structure and composition for understanding the extent of fishing impacts in soft sediment ecosystems. J Sea Res 86: 58-68.

Herbert RJ, Ross K, et al. Intertidal invertebrates and biotopes of Poole Harbour SSSI and survey of Brownsea Island Lagoon, Bournemouth University Report to Natural England, 2010.

Herbert RJ, Willis J, et al. 2012. Invasion in tidal zones on complex coastlines: modelling larvae of the non-native Manila clam, Ruditapes philippinarum, in the UK. J Biogeogr 39: 585-599.

Humphreys J. 2005. 3. Salinity and tides in Poole Harbour: Estuary or lagoon? Proc Mar Sci 7, 35-47.

Humphreys J, Harris MR, et al. 2015. Introduction, dispersal and naturalization of the Manila clam Ruditapes philippinarum in British estuaries, 1980-2010. J Mar Biol Assoc UK 95: 11631172 .

Jensen A, Humphreys J, et al. 2005. 13. The Manila Clam in Poole Harbour, Proc Mar Sci 7: pp. 163-173.

Kaiser MJ, Clarke KR, et al. 2006. Global analysis of response and recovery of benthic biota to fishing. Mar Ecol Prog Ser 311: 1-14.

Kraberg AC, Wasmund N, et al. 2011. Regime shifts in the marine environment: the scientific basis and political context. Mar Pollut Bull 62: 7-20.

Lardicci C, Ceccherelli G, et al. 1997. Streblospio shrubsolii (Polychaeta: Spionidae) temporal fluctuations in size and reproductive activity. Cah Biol Mar 38: 207-214.

Levin SA, Paine RT. 1974. Disturbance, patch formation, and community structure. Proc Natl Acad Sci 71: pp. 2744-2747.

Levin S, Whitfield M. 1994. Patchiness in marine and terrestrial systems: from individuals to populations [and Discussion]. Philos Trans $r$ Soc Lond B: Biol Sci 343: 99-103.

Lindeboom H, de Groot S. 1998. IMPACT-II: The effects of different types of fisheries on the North Sea and Irish Sea benthic ecosystems.

Malvern. 2017. Website: http://www.malvern.com/en/products/prod uct-range/mastersizer-range/mastersizer-3000/. Last Accessed February 2017.

Martín J, Puig P, et al. 2015. Trawling-induced daily sediment resuspension in the flank of a Mediterranean submarine canyon. Deep Sea Res Part II: Top Stud Oceanogr 104: 174-183.

Mayer LM, Schick DF, et al. 1991. Effects of commercial dragging on sedimentary organic matter. Mar Environ Res 31: 249-261.

Meyerson LA, Reaser JK. 2002. Biosecurity: moving toward a comprehensive approach. BioScience 52: 593-600.

Molnar JL, Gamboa RL, et al. 2008. Assessing the global threat of invasive species to marine biodiversity. Front Ecol Environ 6: 485-492.

Mosbahi N, Pezy JP, et al. 2016. Immediate effect of clam harvesting on intertidal benthic communities in the mudflat zones of kneiss islands (central mediterranean sea). J Aquac Res Dev 7: 2.

O'Neill F, Summerbell K. 2011. The mobilisation of sediment by demersal otter trawls. Mar Pollut Bull 62: 1088-1097.

Palanques A, Puig P, et al. 2014. Effects of bottom trawling on the Ebro continental shelf sedimentary system (NW Mediterranean). Cont Shelf Res 72: 83-98.

Parker L, Pinn E. Ecological effects of pump-scoop dredging for cockles on the intertidal benthic communities, The Ecology of Poole Harbour, Elsevier, London, 2005, pp. 205-218.

Pauly D. 1995. Anecdotes and the shifting baseline syndrome of fisheries. Trends Ecol Evol 10: 430. 
Pearson T, Rosenberg R. 1978. Macrobenthic succession in relation to organic enrichment and pollution of the marine environment. Oceanogr Mar Biol Ann Rev 16: 229-311.

Pickett STA, White PS. (eds.). The Ecology of Natural Disturbance and Patch Dynamics. Academic Press, Orlando, FL, 1985, p. 472.

Piersma T, Koolhaas A, et al. 2001. Long-term indirect effects of mechanical cockle-dredging on intertidal bivalve stocks in the Wadden Sea. J Appl Ecol 38: 976-790.

Pinedo S, Sardá R, et al. 2000. Effect of sediment particle size on recruitment of Owenia fusiformis in the Bay of Blanes (NW Mediterranean Sea): an experimental approach to explain field distribution. Mar Ecol Prog Ser 203: 205-213.

Pranovi F, Da Ponte F, et al. 2004. A multidisciplinary study of the immediate effects of mechanical clam harvesting in the Venice Lagoon. ICES J Mar Sci: J Cons 61: 43-52.

Rossi F, Lardicci C. 2002. Role of the nutritive value of sediment in regulating population dynamics of the deposit-feeding polychaete Streblospio shrubsolii. Mar Biol 140: 1129-1138.

Sanders JL, Kendall MA, et al. 2007. Can functional groups be used to indicate estuarine ecological status?Hydrobiologia 588: 45-58.

Sardá R, Martin D. 1993. Populations of Streblospio (Polychaeta: Spionidae) in temperate zones: demography and production. $J$ Mar Biol Assoc UK 73: 769-784.

Scaps P. 2002. A review of the biology, ecology and potential use of the common ragworm Hediste diversicolor (OF Müller) (Annelida: Polychaeta). Hydrobiologia 470: 203-218.

Schwinghamer P, Gordon DC, et al. 1998. Effects of experimental otter trawling on surficial sediment properties of a sandy-bottom ecosystem on the grand banks of Newfoundland. Conserv Biol 12: $1215-1222$.
Sebesvari Z, Esser F, et al. 2006. Sediment-associated cues for larval settlement of the infaunal spionid polychaetes Polydora cornuta and Streblospio benedicti. J Exp Mar Biol Ecol 337: 109-120.

Southern Science. An experimental study on the impact of clam dredging on soft sediment macro invertebrates. Report to English Nature, 1998.

Spencer B, Kaiser M, et al. 1998. Intertidal clam harvesting: benthic community change and recovery. Aquac Res 29: 429-437.

Thistle D. 1981. Natural physical disturbances and communities of marine soft bottoms. Mar Ecol Prog Ser 6: 223-228.

Thrush SF, Hewitt JE, et al. 1998. Disturbance of the marine benthic habitat by commercial fishing: impacts at the scale of the fishery. Ecol Appl 8: pp. 866-879.

Underwood A. 1993. The mechanics of spatially replicated sampling programmes to detect environmental impacts in a variable world. Austral Ecol 18: 99-116.

Utting S, Spencer B. The hatchery culture of bivalve mollusc larvae and juveniles, Ministry of Agriculture, Fisheries and Food, Directorate of Fisheries Research, 1991.

Wallingford HR. Poole Harbour approach channel deepening: hydrodynamic and sedimentation studies. Technical Report EX 4945, Wallingford, UK, 2004.

Warwick RM, Clarke KR. 1993. Increased variability as a symptom of stress in marine communities. J Exp Mar Biol Ecol 172: 215-226.

Wilson FS. 1990. Temporal and spatial patterns of settlement: a field study of molluscs in Bogue Sound, North Carolina. J Exp Mar Biol Ecol 139: 201-220.

WoRMS. 2017. World Register of Marine Species. http://www. marinespecies.org/. Last Accessed: 10th November 2017.

Cite this article as: Clarke LJ, Esteves LS, Stillman RA, Herbert RJH. 2018. Impacts of a novel shellfishing gear on macrobenthos in a marine protected area: pump-scoop dredging in Poole Harbour, UK. Aquat. Living Resour. 31: 5 